
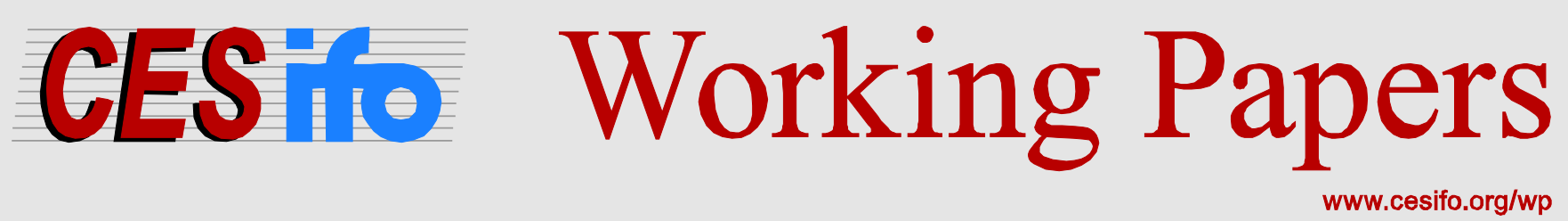

\title{
Incentives to Work and Performance in the Public Sector
}

\author{
George Economides \\ Apostolis Philippopoulos \\ Petros Varthalitis
}

CESIFO WORKING PAPER NO. 5193

CATEGORY 1: PUBliC FinANCE

JANUARY 2015

ISSN 2364-1428

An electronic version of the paper may be downloaded

- from the SSRN website:

- from the RePEc website:

- from the CESifo website:

www.SSRN.com

www.RePEc.org

www.CESifo-group.org/wp

\section{CESifo}




\title{
Incentives to Work and Performance in the Public Sector
}

\begin{abstract}
This paper develops a dynamic general equilibrium model with three distinct social groups, capitalists, private workers and public employees. After solving for the status quo equilibrium, which can mimic the advantages of employment in the public sector in most EU countries, the paper looks for policy reforms that can improve work incentives, and hence enhance productive efficiency, in the public sector. We focus on reforms aiming to establish parity between work conditions in the public and the private sector.
\end{abstract}

JEL-Code: D580.

Keywords: dynamic general equilibrium models, efficiency, equity, employment, incentives.

\author{
George Economides* \\ Athens University of Economics and Business \\ School of Economic Sciences \\ 76 Patission street \\ Greece - Athens 10434 \\ gecon@aueb.gr
}

\author{
Apostolis Philippopoulos \\ Athens University of Economics and \\ Business / School of Economic Sciences \\ 76 Patission street \\ Greece-Athens 10434 \\ aphil@aueb.gr
}

\author{
Petros Varthalitis \\ Athens University of Economics and \\ Business / School of Economic Sciences \\ 76 Patission street \\ Greece-Athens 10434 \\ pvarthalitis@aueb.gr
}

*corresponding author

January 21, 2015

We thank seminar participants, especially Pedro Gomes, at the CESifo Venice Summer Institute on "Reforming the Public Sector” held at Venice, 25-26 July 2014. We also thank Christos Kotsogiannis, Jim Malley, Hyun Park and Vanghelis Vassilatos for discussions. We are grateful to Dimitris Papageorgiou for help with the data. This research is co-financed by the European Union (European Social Fund - ESF) and Greek national funds through the Operational Program "Education and Lifelong Learning" of the National Strategic Reference Framework (NSRF) - Research Funding Program ARISTEIA II_Public Sector Reform_5328; we are grateful for their support. Any views and errors are ours. 


\section{Introduction}

The 2008-2009 crisis and the subsequent sharp rise in sovereign debts in most countries, are forcing governments to reform their public sectors. A particularly debated reform is to establish parity between work conditions in the private and the public sector. For instance, according to the lead article in The Economist, January $8^{\text {th }}$ 2011, "The struggle with public-sector unions should be about productivity and parity, not just spending cuts”. It is thus useful to study the potential efficiency gains, but also the distributional conflicts, arising from such reforms.

It is commonly believed that employment in the public sector "differs" from employment in the private sector. Specifically, jobs in the public sector are far more secure and public employees receive a wide range of (monetary or in kind) benefits on top of their wages that are unrelated to work performance. ${ }^{1}$ This is even if wage differentials between the private and the public sector have been reduced over time. It is natural to expect that such differences play a key role in work incentives and, hence, productive efficiency of the public sector relative to the private sector.

European Union countries provide a clear example. The standard deviation of employment in the public sector is smaller than the standard deviation of employment in the private sector (see Appendix 1) implying a higher degree of job security in the public sector. Besides, there is a lot of anecdotal evidence of extra benefits received by public employees (see e.g. Alesina, 1999, Alesina and Giavazzi, 2006, The Economist, January $8^{\text {th }}$ 2011, while examples of "advantages of government employment” in various countries can be also found in a plethora of web links). ${ }^{2}$ Finally, nowadays, in most EU countries, public employees enjoy on average higher wages than their counterpart workers in the private sector even after controlling for education, age, gender, etc (see e.g. de Castro et al., 2013).

In this paper, we first construct a general equilibrium model that incorporates the above facts. In particular, we construct a modified neoclassical growth model that incorporates three distinct types of agents (capitalists, private workers and public

\footnotetext{
${ }^{1}$ These benefits come in the form of better health insurance, higher pensions, more paid leave (sick, holiday, vacation, etc), student loan repayments, overtime payments, child care subsidies, etc. Advantages of employment in the public sector may also come in the form of reduced working hours and a more relaxed work environment.

${ }^{2}$ Munnell et al. (2011) estimate the value of extra benefits that state-local public sector employees enjoy in the US vis-à-vis their private sector counterparts.
} 
employees) and two sectors (producing private and public goods). Capitalists and private workers are associated with the production of the private good, while public employees and goods purchased from the private sector are used by the government (i.e. by a state-owned enterprise) for the production of the public good. Private workers face job insecurity modeled as in the lotteries literature. When the model is solved numerically using common parameter values and European fiscal data, it can mimic rather well the advantages of employment in the public sector in the EU as discussed above.

In turn, departing from this status quo solution, we study the qualitative and quantitative implications of a number of reforms that aim to strengthen the incentive to work and, hence, improve productive efficiency (measured as an output-to-input ratio) in the public sector. As said, we focus on reforms that establish parity between work conditions in the public and the private sector. In particular, in light of the above empirical evidence, and similarly to the situation in the private sector, we introduce job insecurity in the public sector, link the public wage rate to a measure of labor productivity and change the mix between wages and transfers in favor of the former. We study both the aggregate and distributional implications of these reforms.

Our main results are as follows. Introducing job insecurity, like in the private sector, seems to improve the work incentives of public employees but the importance of this reform is negligible quantitatively. Cutting public wages (for instance, by linking the public wage rate to a measure of labor productivity) deteriorates the work incentives of public employees and this leads to a drop in public output and to trivial effects on the rest of the economy. By contrast, what seems to really help the aggregate economy is a policy reform that equalizes the ratio of non-labor transfers to the wage rate in the two sectors and, at the same time, uses the efficiency savings being enjoyed by the switch to a more efficient economy with a bigger tax base - to cut income taxes. The importance of the ratio of non-labor transfers to the wage rate for work incentives should not come as a surprise: Fang and Rogerson (2011) have already shown the importance of this ratio for hours of work.

Therefore, in our experiments, the main policy task should be to equalize the ratios of non-labor transfers to the wage rate across the public and the private sector. But, as it usually happens with reforms, this does not come as a free lunch: although it is good for the aggregate economy (per capita private and public output, per capita 
welfare and public sector efficiency, they all rise), as well as for other social groups (the net income and welfare of capitalists and private workers rise), public employees are badly hurt relative to the status quo. Their work incentives are improved, but their net income and consumption level are damaged. These distributional consequences can possibly provide an explanation why public sector unions are negative to such reforms. As The Economist, January $8^{\text {th }} 2011$ says, "the immediate battle will be over benefits, not pay, ... and the real issue is parity”.

Then, a natural question to ask is whether we can find a mix of reforms that, although they generate the above social benefits, they are more feasible politically in the sense that they protect the income of public employees. ${ }^{3}$ We show that this can be partially achieved by combining the above mentioned key reform (namely, the equalization of the ratios of non-labor transfers to the wage rate in the two sectors) with an income support policy that keeps the wage rate in the public sector above a minimum value. For instance, setting the wage rate in the public sector equal to the wage rate in the private sector, in combination with the above mentioned key reform, allows a rise in the net income and consumption levels of capitalists and private workers without hurting a lot the net income and consumption of public employees, which remain close to their status quo levels. Public employees get worse off in terms of utility, partially because of the lower consumption they enjoy relative to the status quo, but, mainly, because they have to work harder than in the status quo. On the negative side, this new mix of reforms comes at the cost of relatively smaller gains in aggregate productive efficiency, whereas public sector productive efficiency remains close to the status quo level.

The bottom line is that, although there are social options, at the end of the day, there is a value judgment to be made. It is hard to find Pareto efficient reforms. In other words, we cannot find a way of improving everything without making something else worse. As it happens in most cases, there is a tradeoff between efficiency and distribution. But, on the positive side, we can find policy mixes that mitigate the distributional costs. The problem, as Wren-Lewis (2010) points out, is that policy mixes are not well understood by the public and any mix of policies becomes an unproductive battle between the political Right and the political Left.

\footnotetext{
${ }^{3}$ This is consistent with the suggestion of Diamond and Saez (2011) in the sense that reforms are implementable only if they are socially acceptable and not too complex.
} 
The rest of the paper is as follows. Section 2 describes the economic environment. Section 3 solves for the status quo economy. Reforms are studied in section 4. Section 5 closes the paper. An Appendix includes technical details.

\section{Informal description of the model}

Our vehicle of analysis is a modified neoclassical growth model of a closed economy. The model comprises three social classes, called capitalists, private workers and public employees (for similar models, see e.g. Ardagna, 2007, and Economides et al., 2013 and 2014). Time is discrete and infinite. The model is deterministic for simplicity.

\subsection{Population shares and households' roles}

The population size at time $t$ is $N_{t}$. Among $N_{t}$, there is a pool of identical capitalists or entrepreneurs $k=1,2, \ldots, N_{t}^{k}$, a pool of identical private workers $w=1,2, \ldots, N_{t}^{w}$ and a pool of identical public employees or bureaucrats $b=1,2, \ldots, N_{t}^{b}$, where $N_{t}^{k}+N_{t}^{w}+N_{t}^{b}=N_{t}$ at each $t$. Capitalists own the private firms, hold capital and government bonds and also receive labor income for their managerial services. Private workers work in the private sector facing a non-zero probability of losing their jobs. Public employees work in the public sector with probability one. For simplicity, only capitalists save in the form of capital or bonds. There are also $f=1,2, \ldots, N_{t}^{f}$ identical private firms owned by the capitalists. The number of capitalists equals the number of private firms or each firm is run by a capitalist. For simplicity, the fractions of the three agents in total population are exogenously set and remain constant over time. We also rule out occupational choice and mobility across groups. ${ }^{4}$

\subsection{Production of private and public goods}

Private goods are produced by private firms. These firms choose capital, supplied by capitalists, and labour services, supplied by both capitalists and private workers. They also make use of public infrastructure. Public goods are produced by the government. 
To do so, the government purchases part of the private good produced and hires public employees. ${ }^{5}$ Public goods and services provide utility-enhancing services to households and productivity-enhancing services to private firms. In order to finance its various types of public spending, the government levies distorting taxes and issues bonds.

\subsection{How private and public workers differ and how we model job insecurity}

Public and private employees can differ in wages, non-labor benefits received and job security. Regarding the degree of job security, in the status quo economy, we assume that only private workers face job insecurity. Then, in the reformed economy, one possible reform will be to allow for job insecurity in the public sector too.

To model job insecurity, we will use the employment lotteries model of Hansen (1985) and Rogerson (1988) and also used by e.g. Hansen and Prescott (1995). Thus, agents face an exogenous employment lottery that determines whether or not they are employed. Although this is a rather stylized model of unemployment, it keeps the algebra simple and allows minimal deviations from both the associated market-clearing paradigm and the related literature on public employment. Details are in subsection 3.2 below.

\section{The model (status quo economy)}

This section formalizes the above story. As said above, in the status quo, only private workers face job insecurity.

\subsection{Capitalists' problem}

The lifetime utility of each capitalist $k=1,2, \ldots, N_{t}^{k}$ is:

$$
\sum_{t=0}^{\infty} \beta^{t} u\left(c_{t}^{k}, e_{t}^{k}, \bar{Y}_{t}^{g}\right)
$$

\footnotetext{
${ }^{4}$ See e.g. Acemoglu (2009, chapter 23) for occupational choice in a model with capitalists and workers. See e.g. Cavalcanti and Dos Santos (2014) for a model of occupational choice with public employees.
} 
where $c_{t}^{k}$ and $e_{t}^{k}$ are each $k$ 's consumption and work effort respectively, $\bar{Y}_{t}^{g}$ is per household public goods and services (i.e. $\bar{Y}_{t}^{g} \equiv \frac{Y_{t}^{g}}{N_{t}}$ ) and $0<\beta<1$ is a time preference parameter. In what follows, it is more intuitive to assume that that those employed work a fixed shift length of $h>0$ hours so that the disutility from working a shift of length $h$ with a degree of effort $e_{t}$ is measured by $h e_{t}$. Thus, hours of leisure, for those currently employed, is $1-h e_{t}$ where 1 is the total time endowment. For our numerical solutions below, we will use a period utility function of the additive form:

$u\left(c_{t}^{k}, e_{t}^{k} ; \bar{Y}_{t}^{g}\right)=\mu_{1} \log c_{t}^{k}+\mu_{2} \log \left(1-h e_{t}^{k}\right)+\left(1-\mu_{1}-\mu_{2}\right) \log \bar{Y}_{t}^{g}$

where $0<\mu_{1}, \mu_{2}<1$ are standard preference parameters.

Each $k$ enters period $t$ with predetermined holdings of physical capital and government bonds, $k_{t}^{k}$ and $b_{t}^{k}$, whose gross returns are $r_{t}$ and $i_{t}$ respectively. The within-period budget constraint of each $k$ is:

$$
\left(1+\tau_{t}^{c}\right) c_{t}^{k}+k_{t+1}^{k}-(1-\delta) k_{t}^{k}+b_{t+1}^{k}-b_{t}^{k}=\left(1-\tau_{t}^{k}\right)\left(r_{t} k_{t}^{k}+\pi_{t}^{k}\right)+\left(1-\tau_{t}^{l}\right) w_{t}^{k} e_{t}^{k} h+i_{t} b_{t}^{k}+\bar{G}_{t}^{t r, k}
$$

where $0<\delta<1$ is the capital depreciation rate, $\pi_{t}^{k}$ is dividends received from private firms, $w_{t}^{k}$ is the wage rate earned by capitalists, $\bar{G}_{t}^{t r, k}$ is government transfers to each $k$ and $0<\tau_{t}^{k}, \tau_{t}^{l}, \tau_{t}^{c}<1$, are the tax rates on capital income, labor income and private consumption respectively.

Each $k$ chooses $\left\{c_{t}^{k}, k_{t+1}^{k}, b_{t+1}^{k}, e_{t}^{k}\right\}_{t=0}^{\infty}$ acting competitively. The first-order conditions include the budget constraint in (3) and:

\footnotetext{
${ }^{5}$ This should be contrasted to most of the literature where it is typically assumed that the government transforms units of private goods into units of public goods at a one-to-one rate.
} 


$$
\begin{aligned}
& \frac{\mu_{2}}{\left(1-h e_{t}^{k}\right)}=\frac{\mu_{1}\left(1-\tau_{t}^{l}\right) w_{t}^{k}}{\left(1+\tau_{t}^{c}\right) c_{t}^{k}} \\
& \frac{\left(1+\tau_{t+1}^{c}\right) c_{t+1}^{k}}{\left(1+\tau_{t}^{c}\right) c_{t}^{k}}=\beta\left[1-\delta+\left(1-\tau_{t+1}^{k}\right) r_{t+1}\right] \\
& \frac{\left(1+\tau_{t+1}^{c}\right) c_{t+1}^{k}}{\left(1+\tau_{t}^{c}\right) c_{t}^{k}}=\beta\left(1+i_{t+1}\right)
\end{aligned}
$$

where (4a) is a labor supply condition, while (4b) and (4c) are standard Euler equations for capital and government bonds respectively.

\subsection{Private workers' problem}

As said above, private workers face employment uncertainty modeled as in the lotteries model of Hansen (1985), Rogerson (1988) and Hansen and Prescott (1995). In particular, following this literature, we assume that each private worker $w=1,2, \ldots, N_{t}^{w}$ faces an exogenous probability $0 \leq \varphi \leq 1$ of retaining his/her job and an exogenous probability $0 \leq 1-\varphi \leq 1$ of losing his/her job in each time period. Following the same literature, we also assume that the worker can insure himself/herself through optimally chosen private unemployment insurance. ${ }^{6}$ The worker makes his/her decisions (including employment contracts) prior to the lottery draw. $^{7}$

The lifetime utility of each private worker, $w=1,2, \ldots, N_{t}^{w}$, is:

$$
\sum_{t=0}^{\infty} \beta^{t} u\left(c_{t}^{w}, e_{t}^{w}, \bar{Y}_{t}^{g}\right)
$$

where $c_{t}^{w}$ and $e_{t}^{w}$ are $w$ 's consumption and work effort respectively. For our numerical solutions below, we will again use:

\footnotetext{
${ }^{6}$ We could alternatively assume that there is a representative family of workers whose members can be employed with probability $\phi$, or unemployed with probability $1-\phi$ (see e.g. Cole and Ohanian, 2004, for this device although in a different problem); the results would be the same. Also note that we could alternatively use private savings instead of private unemployment insurance; again, the main results would not change but the model is algebraically simpler if we assume that workers do not participate in asset markets.
} 
$u\left(c_{t}^{w}, e_{t}^{w} ; \bar{Y}_{t}^{g}\right)=\mu_{1} \log c_{t}^{w}+\mu_{2} \log \left(1-h e_{t}^{w}\right)+\left(1-\mu_{1}-\mu_{2}\right) \log \bar{Y}_{t}^{g}$

If the worker is employed, which happens with probability $0<\varphi \leq 1$, the budget constraint is:

$\left(1+\tau_{t}^{c}\right) c_{t}^{w, e}+\mu_{t}^{w} \bar{y}_{t}^{w}=\left(1-\tau_{t}^{l}\right) w_{t}^{w} e_{t}^{w} h+\bar{G}_{t}^{t r, w}$

while, if the worker loses his/her job, which happens with probability $0 \leq 1-\varphi<1$, the budget constraint is:

$\left(1+\tau_{t}^{c}\right) c_{t}^{w, u}+\mu_{t}^{w} \bar{y}_{t}^{w}=\bar{y}_{t}^{w}+\bar{G}_{t}^{t r, u}$

where $c_{t}^{w, e}$ and $c_{t}^{w, u}$ are consumption when the worker is employed and unemployed respectively, $w_{t}^{w}$ is the wage rate earned by private workers when employed, $\bar{G}_{t}^{t r, w}$ is government transfers to each private worker when employed, $\bar{G}_{t}^{t r, u}$ is government transfers to each agent when unemployed, $\bar{y}_{t}^{w}$ is the worker's private unemployment insurance whose price is denoted as $\mu_{t}^{w} .8$

We solve the problem working as in e.g. Rogerson (1988) and Hansen and Prescott (1995). Thus, in each period, the private worker maximizes expected utility:

$\varphi\left[\mu_{1} \log c_{t}^{w, e}+\mu_{2} \log \left(1-h e_{t}^{w}\right)+\left(1-\mu_{1}-\mu_{2}\right) \log \bar{Y}_{t}^{g}\right]+(1-\varphi)\left[\mu_{1} \log c_{t}^{w, u}+\left(1-\mu_{1}-\mu_{2}\right) \log \bar{Y}_{t}^{g}\right]$

subject to the single expected budget constraint:

\footnotetext{
${ }^{7}$ See e.g. Hassler et al. (2005) for a case in which private decisions are made after current uncertainty is realized.

${ }^{8}$ Thus, we also allow for government unemployment insurance via a transfer program. A difference of government insurance from private insurance is that, while private contracts are privately optimally chosen, the government forces agents to be part of its transfer program by financing its spending by compulsory and general taxation. See also Hassler et al. (2005) for the coexistence of both private and public unemployment insurance in modern societies. We are aware of course that if private insurance markets are complete, then full risk sharing is achieved via these markers so that progressive taxation or government insurance provides no additional insurance gain (see Krueger and Perri, 2011).
} 
$\varphi\left(1+\tau_{t}^{c}\right) c_{t}^{w, e}+(1-\varphi)\left(1+\tau_{t}^{c}\right) c_{t}^{w, u}+\mu_{t}^{w} \bar{y}_{t}^{w}=\varphi\left(1-\tau_{t}^{l}\right) w_{t}^{w} e_{t}^{w} h+\varphi \bar{G}_{t}^{t r, w}+(1-\varphi) \bar{y}_{t}^{w}+(1-\varphi) \bar{G}_{t}^{t r, u}$

Each $w$ chooses $\left\{c_{t}^{w, e}, c_{t}^{w, u}, e_{t}^{w}, \bar{y}_{t}^{w}\right\}_{t=0}^{\infty}$ acting competitively. The first-order conditions include the budget constraint in (9) and:

$c_{t}^{w, e}=c_{t}^{w, u} \equiv c_{t}^{w}$

$\frac{\mu_{2}}{\left(1-h e_{t}^{w}\right)}=\frac{\mu_{1}\left(1-\tau_{t}^{l}\right) w_{t}^{w}}{\left(1+\tau_{t}^{c}\right) c_{t}^{w, e}}$

$\mu_{t}^{w}=1-\varphi$

where (10a) implies that private insurance allows consumption smoothing across different employment states, (10b) is a standard labor supply condition and (10c) equates costs and benefits of private insurance.

If we combine these first-order conditions, $(10 \mathrm{~b})$ can be rewritten as:

$\frac{\mu_{2}}{\left(1-h e_{t}^{w}\right)}=\frac{\mu_{1}\left(1-\tau_{t}^{l}\right) w_{t}^{w}}{\varphi\left(1-\tau_{t}^{l}\right) w_{t}^{w} h e_{t}^{w}+\varphi \bar{G}_{t}^{t r, w}+(1-\varphi) \bar{G}_{t}^{t r, u}}$

which implies that work effort decreases with $\frac{\bar{G}_{t}^{t r, w}}{\left(1-\tau_{t}^{l}\right) w_{t}^{w}}, \frac{\bar{G}_{t}^{t r, u}}{\left(1-\tau_{t}^{l}\right) w_{t}^{w}}$ and $\varphi$. That is, work effort, or hours of work, fall when transfers relative to net-of-tax labor income rise or when job security rises. Keep in mind that these are direct effects holding everything else constant. The overall, or general, equilibrium effects associated with changes in tax rates, etc, are studied below. All this is conceptually similar to Fang and Rogerson (2011), although these authors focus on the effects of labor tax rate on work hours and also abstain from job insecurity issues.

\subsection{Public employees' problem}

Public employees are modeled similarly to private employees with the exception that (in the status quo economy) they do not face job insecurity. Thus, the lifetime utility of each $b=1,2, \ldots, N_{t}^{b}$ is: 
$\sum_{t=0}^{\infty} \beta^{t} u\left(c_{t}^{b}, e_{t}^{b}, \bar{Y}_{t}^{g}\right)$

where $c_{t}^{b}$ and $e_{t}^{b}$ are $b$ 's consumption and work effort respectively. For our numerical solutions below, we will again use:

$u\left(c_{t}^{b}, e_{t}^{b} ; \bar{Y}_{t}^{g}\right)=\mu_{1} \log c_{t}^{b}+\mu_{2} \log \left(1-h e_{t}^{b}\right)+\left(1-\mu_{1}-\mu_{2}\right) \log \bar{Y}_{t}^{g}$

subject to the budget constraint:

$\left(1+\tau_{t}^{c}\right) c_{t}^{b}=\left(1-\tau_{t}^{l}\right) w_{t}^{g} e_{t}^{b} h+\bar{G}_{t}^{t r, b}$

where $w_{t}^{g}$ is the wage rate in the public sector and $\bar{G}_{t}^{t r, b}$ is government transfers to each public employee.

Each $b$ chooses $\left\{c_{t}^{b, e}, c_{t}^{b, u}, e_{t}^{b}, \bar{y}_{t}^{b}\right\}_{t=0}^{\infty}$ acting competitively. The first-order conditions include the budget constraint in (14) and the condition for work effort:

$\frac{\mu_{2}}{\left(1-h e_{t}^{b}\right)}=\frac{\mu_{1}\left(1-\tau_{t}^{l}\right) w_{t}^{g}}{\left(1+\tau_{t}^{c}\right) c_{t}^{b, e}}$

which, using the budget constraint, can be rewritten as:

$$
\frac{\mu_{2}}{\left(1-h e_{t}^{b}\right)}=\frac{\mu_{1}\left(1-\tau_{t}^{l}\right) w_{t}^{g}}{\left(1-\tau_{t}^{l}\right) w_{t}^{g} h e_{t}^{b}+\bar{G}_{t}^{t r, b}}
$$

It is useful for what follows, to compare (16) to (11). Inspection of these two equations implies that work effort in the private sector and work effort in the public sector can differ because of differences in: (i) the degree of job security, $\varphi<1$; (ii) the wage rate $w_{t}^{w} \neq w_{t}^{g}$; (iii) the ratio of non-labor benefits to wages, $\frac{\bar{G}_{t}^{t r, w}}{w_{t}^{w}} \neq \frac{\bar{G}_{t}^{t r, b}}{w_{t}^{g}}$. One of them, or a combination of them, is enough to cause differences between work effort 
in the private sector and work effort in the public sector. Recall that this is consistent with the motivation of the paper in the Introduction.

\subsection{Private firms and production of the private good}

In each period, each private firm $f=1,2, \ldots, N_{t}^{f}$ chooses capital, $k_{t}^{f}$, and the two types of labor services, $e_{t}^{f, k}$ and $e_{t}^{f, w}$, to maximize period-by-period profits:

$\pi_{t}^{f}=y_{t}^{f}-r_{t} k_{t}^{f}-w_{t}^{w} e_{t}^{f, w}-w_{t}^{k} e_{t}^{f, k}$

where, for our numerical solutions below, we will use a production function of the form:

$y_{t}^{f}=A\left(k_{t}^{f}\right)^{\alpha_{1}}\left(A^{k} e_{t}^{f, k}+A^{w} e_{t}^{f, w}\right)^{\alpha_{2}}\left(\frac{Y_{t}^{g}}{N_{t}^{f}}\right)^{1-\alpha_{1}-\alpha_{2}}$

where $A, A^{k}, A^{w}>0$ and $0<\alpha_{1}, \alpha_{2}<1$ are technology parameters. The part of the production function related to the labor input is modeled as in Hornstein et al. (2005) while here we also allow the public good to provide production services as in e.g. Barro (1990). We report that none of these assumptions is important to our main results.

The firm’s first-order conditions are simply:

$$
\begin{aligned}
& r_{t}=\alpha_{1} \frac{y_{t}^{f}}{k_{t}^{f}} \\
& w_{t}^{w}=\alpha_{2} A^{w} \frac{y_{t}^{f}}{\left(A^{k} e_{t}^{f, k}+A^{w} e_{t}^{f, w}\right)} \\
& w_{t}^{k}=\alpha_{2} A^{k} \frac{y_{t}^{f}}{\left(A^{k} e_{t}^{f, k}+A^{w} e_{t}^{f, w}\right)}
\end{aligned}
$$

so that profits are:

$$
\pi_{t}^{f}=\left(1-\alpha_{1}-\alpha_{2}\right) y_{t}^{f}
$$




\subsection{Government budget constraint and policy instruments}

The period budget constraint of the government is (aggregate quantities are denoted by capital-letters):

$G_{t}^{g}+G_{t}^{w}+G_{t}^{t r, k}+G_{t}^{t r, w}+G_{t}^{t r, b}+G_{t}^{t r, u}+\left(1+i_{t}\right) B_{t}=B_{t+1}+T_{t}$

where $G_{t}^{g}$ is total public spending on goods and services purchased from the private sector, $G_{t}^{w}$ is the total public wage bill, $G_{t}^{t r, k}, G_{t}^{t r, w}, G_{t}^{t r, b}$ and $G_{t}^{t r, u}$ are respectively transfers to capitalists, private workers, public employees and the unemployed, $B_{t}$ is the beginning-of-period total stock of government bonds and $T_{t}$ is total tax revenues. Notice that that the output shares of $G_{t}^{g}, G_{t}^{w}, G_{t}^{t r}$ (where $G_{t}^{t r}=G_{t}^{t r, k}+G_{t}^{t r, w}+G_{t}^{t r, b}$ is total transfers) and $G_{t}^{t r, u}$ will be set as in the data (see below for details).

Total tax revenues, $T_{t}$, are:

$T_{t} \equiv \tau_{t}^{c}\left(N_{t}^{k} c_{t}^{k}+N_{t}^{w} c_{t}^{w}+N_{t}^{b} c_{t}^{b}\right)+\tau_{t}^{k} N_{t}^{k}\left(r_{t} k_{t}^{k}+\pi_{t}^{k}\right)+\tau_{t}^{l}\left(N_{t}^{k} w_{t}^{k} e_{t}^{k} h+\varphi N_{t}^{w} w_{t}^{w} e_{t}^{w} h+N_{t}^{b} w_{t}^{g} e_{t}^{b} h\right)$

Therefore, as in e.g. Alesina et al. (2002), we include the three main types of government spending (purchases of goods and services from the private sector, public wages, and transfers to individuals). We also include the three main types of taxes (taxes on consumption, capital income and labor income).

Inspection of (20a-b) implies that, in each time period, there are eleven policy instruments $\left(G_{t}^{g}, G_{t}^{w}, G_{t}^{t r, k}, G_{t}^{t r, w}, G_{t}^{t r, b}, G_{t}^{t r, u}, \tau_{t}^{c}, \tau_{t}^{k}, \tau_{t}^{l}, B_{t+1}, N_{t}^{b}\right)$ out of which one has to adjust residually to satisfy the government budget constraint. Following most of the related literature, we will assume that, along the transition path, the adjusting instrument is the end-of-period public debt, $B_{t+1}$, so that the rest can be set exogenously by the government. Instead, in the steady state, we will set the debt-tooutput ratio as in the data and allow the labor tax rate to be the residually determined instrument (see also e.g. Mendoza and Tesar, 2005, in a model for the European Union). 
For convenience, concerning public spending instruments, we will work in terms of their GDP shares. Thus, we define $s_{t}^{g} \equiv \frac{G_{t}^{g}}{Y_{t}}, s_{t}^{w} \equiv \frac{G_{t}^{w}}{Y_{t}}, s_{t}^{t r, k} \equiv \frac{G_{t}^{t r, k}}{Y_{t}}$, $s_{t}^{t r, w} \equiv \frac{G_{t}^{t r, w}}{Y_{t}}, \quad s_{t}^{t r, b} \equiv \frac{G_{t}^{t r, b}}{Y_{t}}$, and $s_{t}^{t r, u} \equiv \frac{G_{t}^{t r, u}}{Y_{t}} \quad$, where $Y_{t}$ denotes total output (see Appendix 2 for details). Similarly, concerning the number of public employees, we will work in terms of their population share, $v_{t}^{b} \equiv \frac{N_{t}^{b}}{N_{t}}$. It is convenient for what follows to define also the population share of capitalists, $v_{t}^{k} \equiv \frac{N_{t}^{k}}{N_{t}}$. Then, the population share of workers follows residually, $v_{t}^{w} \equiv \frac{N_{t}^{w}}{N_{t}}=1-v_{t}^{k}-v_{t}^{b}$.

\subsection{State-owned enterprise and the production of public goods}

Following most of the related literature, ${ }^{9}$ we assume that total public goods and services, $Y_{t}^{g}$, are produced using goods and services purchased from the private sector, $G_{t}^{g}$, and total public employment, $L_{t}^{g}$. In particular, following e.g. Linnemann (2009) and Economides et al. (2013, 2014), we use a Cobb-Douglas production function of the form:

$Y_{t}^{g}=A\left(G_{t}^{g}\right)^{\theta}\left(L_{t}^{g}\right)^{1-\theta}$

where $0 \leq \theta \leq 1$ is a technology parameter. Notice that both private and public good production face the same TFP; this is because we do not want our results to be driven by exogenous factors. The total cost of public production, $G_{t}^{g}+w_{t}^{g} L_{t}^{g}$, is financed by the government through taxes and bonds (see the government budget constraint (20a) above).

\footnotetext{
${ }^{9}$ See Economides et al. (2014) for details and a review of the literature on the production function of public goods. We report that our results are robust to adding public capital, whose changes are financed by public investment spending, as a third factor into the production function of public goods. Again, see Economides et al. (2014) for the role of public capital in public good production functions.
} 


\subsection{Decentralized competitive equilibrium (DCE) of the status quo economy}

Combining the above, we now solve for a DCE. This is for any feasible policy. In this DCE: (i) all types of households maximize utility acting competitively; (ii) all firms in the private sector maximize profits acting competitively; (iii) the insurance company maximizes profits acting competitively (see Appendix 3 for details); (iv) all constraints are satisfied and (v) all markets clear (see Appendix 4 for details); (vi) the amounts, expressed as shares of output, spent by the public enterprise on inputs used for the production of the public good, $s_{t}^{g}$ and $s_{t}^{w}$, are set exogenously at their data average values (see below). When $\left\{s_{t}^{g}, s_{t}^{w}, s_{t}^{t r, k}, s_{t}^{t r, w}, s_{t}^{t r b}, s_{t}^{t r, u}, \tau_{t}^{c}, \tau_{t}^{k}, \tau_{t}^{l}, \nu_{t}^{b}\right\}_{t=0}^{\infty}$ are set by the government, we end up with a dynamic system of 16 equations in 16 endogenous variables, $\left\{c_{t}^{k}, c_{t}^{w}, c_{t}^{b}, k_{t+1}^{k}, b_{t+1}^{k}, e_{t}^{k}, e_{t}^{w}, e_{t}^{b}, y_{t}^{f}, y_{t}^{g}, r_{t}, i_{t}, w_{t}^{w}, w_{t}^{k}, w_{t}^{g}, \pi_{t}^{k}\right\}_{t=0}^{\infty}$. This equilibrium system is presented in Appendix 5. It is solved numerically first for the steady state and then for its transition path when linearized around the steady state. In the steady state, the public debt to GDP ratio is set as in the data and the labour tax rate plays the role of the residually determined fiscal policy variable.

\subsection{Numerical solution of the status quo economy}

In this subsection, we provide a numerical solution of the above economy. We start with parameterization.

\subsubsection{Parameter values and policy instruments}

Since the nature of our numerical solutions is mainly illustrative, our parameterization is chosen in a simple fashion. Regarding parameters for technology and preferences, we use common values. Regarding policy variables, we use data averages of the Eurozone over 2000-2012 (the data source is Eurostat). These values are shown in Table 1 . The time unit is meant to be a year. We report that our main results are robust to changes in parameter values.

Table 1 around here

Baseline parameterization

Let us briefly discuss the parameter and policy values summarized in Table 1 . In the private sector production function, the Cobb-Douglas exponents of labour and 
capital are set at 0.64 and 0.33 respectively, while the exponent of public capital is set at 0.03 , which is close to the public infrastructure investment as share of output in the data (0.025). The TFP parameter, $A$, is normalized at 1 . The time preference rate, $\beta$, is set at 0.99 . The weight given to public goods and services in the utility function is set at 0.1 , which is within the range used in the related literature. ${ }^{10}$ The other preference parameters related to private consumption and leisure, $\mu_{1}$ and $\mu_{2}$, are set at 0.3 and 0.6 respectively; these parameter values imply hours of work within usual ranges. The capital depreciation rate, $\delta$, is set at 0.05 . In the public sector production function, the share of public employment vis-à-vis the share of goods purchased from the private sector, $1-\theta$, is set at 0.569 . This value is the sample average of payments to public wages as a share of total public payments to inputs used in the production of public goods, namely $0.569=s^{w} /\left(s^{w}+s^{g}\right)$, where the values of $s^{w}$ and $s^{g}$ in the data are reported below (for similar calibration practice, see the real business cycle literature and, in related models, see e.g. Linnemann, 2009, and Economides et al., 2013). We also set $A^{k}=A^{w} \equiv 1$ so that capitalists and private workers offer the type of labor services and get the same wage rate in the private sector. As said above, our qualitative results are robust to changes in all parameter values, including the (relatively unknown) value of $1-\theta$.

Regarding policy variables, the share of public employees in total population, $v^{b}$, is set at 0.215 , which is the average value in the data. The share of capitalists, defined as those self-employed, is set at 0.148 again as in the data. The data values of the output share of public spending on public wage payments, $s_{t}^{w}$, on goods and services purchased from the private sector, $s_{t}^{g}$, on total transfers, $s_{t}^{t r}$, and on unemployment benefits, $s_{t}^{t r, u}$, are respectively $0.132,0.10,0.217$ and 0.011 . The effective tax rates on consumption, capital income and labor income, $\tau_{t}^{c}, \tau_{t}^{k}$ and $\tau_{t}^{l}$, are respectively $0.1938,0.2903$ and 0.378 in the data, while, in the steady state, the public debt to GDP ratio is set at 0.9 .

Regarding the (relatively unknown in the data) allocation of total government transfers $\left(s_{t}^{t r}\right)$ among the three social groups $\left(s_{t}^{t r, k}, s_{t}^{t r, w}\right.$ and $\left.s_{t}^{t r, b}\right)$, we adjust the share

\footnotetext{
${ }^{10}$ Chari et al. (1995) use a zero value. On the other hand, Guo and Lansing (1999) use a high value, around 0.36 , in a similar utility function.
} 
of transfers going to public employees $\left(s_{t}^{t r, b}\right)$ vis-à-vis the share of transfers going to private agents $\left(s_{t}^{t r, k}\right.$ and $\left.s_{t}^{t r, w}\right)$ so as to hit the public wage premium observed in the recent European data. In particular, following the detailed study of de Castro et al. (2013), we target the value of 1.03 for the ratio of the public wage rate to the private wage rate. This in turn implies an almost equal allocation of transfers between public and private agents (in particular, public employees receive $50.8 \%$ of total transfers). Notice, however, that since public employees constitute only $21.5 \%$ of the working population, this means that they receive the lion's share of government transfers, as one would expect (see the Introduction). In turn, we exogenously allocate the remaining share of transfers (49.2\%) going to the two private groups (namely, entrepreneurs and workers) according to their population shares as shown in Table 1. We report, however, that our main results are not sensitive to the specific value of the public wage premium used in the status quo economy. ${ }^{11}$

\subsubsection{Steady state solution of the status quo economy}

Given the parameter and policy values in Table 1, the steady state solution of the status quo economy is reported in Table 2 (where the key variables are shown in bold). We also report that, when linearized around the steady state, the model is saddle-path stable.

Table 2 around here

Steady state solution of the status quo economy

The solution in Table 2 is well defined and does relatively well at mimicking the GDP ratios of key macroeconomic aggregates like consumption and capital. More importantly, in this solution, private workers work harder but consume less than public employees. As a result, in terms of utility, public employees are better off than private workers, while it is the capitalists (or "the rich") that enjoy the highest utility level. We believe that all this is consistent with the common belief that, in most European countries, public employees are the winners in terms of wages, transfers and

\footnotetext{
${ }^{11}$ In a previous version of the paper, we parameterized the model assuming that, in the status quo, the public wage rate was lower than the private wage rate (this is the case in the US and in a number of European countries); the qualitative effects of reforms do not depend on this. We also parameterized the model so as workers were indifferent (either in terms of steady state consumption or in terms of
} 
job security relative to their counterparts in the private sector (see the papers in the Introduction). In the context of our model, this can be rationalized by the implicit assumption that there is a ration of government jobs. It is also worth noticing that productive efficiency in the public sector is lower than in the private sector, where productive efficiency is typically measured as an output-to-input ratio (see Appendix 6 for details). ${ }^{12}$

\section{Policy reforms}

In this section, departing from the above steady state solution of the status quo economy, we study the implications of various exogenous changes in fiscal policy. Motivated by the discussion in the Introduction, the aim is to study the effects of policy changes aiming at parity. As we saw in the theoretical model above, work effort in the public sector and work effort in the private sector can differ because of differences in the degree of job security, the wage rate earned and the amount of income that is being received as a transfer relative to the wage rate. Hence, we will study what happens when private workers and public employees are at par regarding the degree of job security, the manner the wage rate is determined and the ratio of non-labor transfers to the wage rate.

\subsection{Policy reforms studied}

The reforms studied are listed in Table 3. To understand the logic of our results, and following usual practice, we start by experimenting with one reform at a time and only in turn study reform mixes.

Table 3 around here Description of policy reforms

In Reform no. 1, we add job insecurity in the public sector like in the private sector. Thus, now public employees know that can keep their job with a nonzero

\footnotetext{
steady state utility) between working in the private sector or the public sector in the status quo economy. Again the qualitative effects of reforms do not depend on this.

${ }^{12}$ See Afonso et al. (2005) and Angelopoulos et al. (2008) for computations of public sector efficiency in various countries and various policy areas. On the other hand, see Pestieau (2007) and Sørensen (2014) for a critical review and methodology issues.
} 
probability $0<q<1$ only, like their counterparts do in the private sector (see subsection 4.2 below for modeling details). In particular, we set $q=\varphi=0.9$, meaning that both private workers and public employees fear that there is a probability $10 \%$ of losing their jobs. Since we do not want the ex ante employed public employees to receive higher per capita wages simply because their number has been decreased, we also cut the exogenously set output share of public wages, $s_{t}^{w}$, by $10 \%$.

Reform no. 2 postulates that the wage rate in the public sector is set in a manner similar to that in the private sector. Specifically, we assume that the wage rate in the public sector equals a measure of the marginal product of labor in this sector, $w_{t}^{g}=\frac{(1-\theta) Y_{t}^{g}}{L_{t}^{g}}$. Algebraically, this adds an extra equation to the equilibrium system. We thus also have a new extra endogenous variable and, given the nature of the extra equation, we find it natural to choose the share of public spending going to public wages, $s_{t}^{w}$, to play the role of the extra endogenous variable.

Reform no. 3 postulates that the ratio of non-labor transfers to the wage rate is equal in the two sectors, $\frac{\bar{G}_{t}^{t r, w}}{w_{t}^{w}}=\frac{\bar{G}_{t}^{t r, b}}{w_{t}^{g}}$. Again this adds an extra equation to the system and we now choose the share of transfers allocated to public employees, $s_{t}^{t r, b}$, to play the role of the new extra endogenous variable.

Reform no. 4 is a mix of reforms that simply combines reforms 1,2 and 3 together.

Reform no. 5 is like no. 4 with the exception that now the wage rate is assumed to be proportional to the wage rate in the private sector, where the degree of proportionality will be specified below. That is, instead of assuming $w_{t}^{g}=\frac{(1-\theta) Y_{t}^{g}}{L_{t}^{g}}$ as in Reform no. 4, we postulate a link between wages in the two sectors, $w_{t}^{g}=\rho w_{t}^{p}$, where $0<\rho \leq 1$ is the degree of proportionality. Our interest in this reform is explained below. ${ }^{13}$

\footnotetext{
${ }^{13}$ This rule, which is in terms of wages, $w_{t}^{g}=\rho w_{t}^{p}$, is equivalent to a rule in terms of transfers, $\bar{G}_{t}^{t r, b}=\rho \bar{G}_{t}^{t r, w}$, given that we also have $\frac{\bar{G}_{t}^{t r, w}}{w_{t}^{w}}=\frac{\bar{G}_{t}^{t r, b}}{w_{t}^{g}}$.
} 


\subsection{Adding job insecurity in the public sector and the new equilibrium system}

In terms of modeling, the main new ingredient is to add job insecurity in the public sector. We thus now assume that both private workers and public employees face job uncertainty and make their decisions prior to the lottery draw. In what follows, we only model what changes relative to the status quo model in the previous section.

Public sector employees, $b=1,2, \ldots, N_{t}^{b}$, are now modeled similarly to private workers. Thus, if we denote by $0<q \leq 1$ the probability that a public employee keeps his/her job, while $0<1-q \leq 1$ is the probability of losing his/her job, then with probability $0<q \leq 1$, the budget constraint is:

$$
\left(1+\tau_{t}^{c}\right) c_{t}^{b, e}+\mu_{t}^{b} \bar{y}_{t}^{b}=\left(1-\tau_{t}^{l}\right) w_{t}^{g} e_{t}^{b} h+\bar{G}_{t}^{t r, b}
$$

while, with probability $0<1-q \leq 1$, the budget constraint is:

$$
\left(1+\tau_{t}^{c}\right) c_{t}^{b, u}+\mu_{t}^{b} \bar{y}_{t}^{b}=\bar{y}_{t}^{b}+\bar{G}_{t}^{t r, u}
$$

where, as above, $c_{t}^{b, e}$ and $c_{t}^{b, u}$ are consumption when the public employee is employed and unemployed respectively, $\bar{G}_{t}^{t r, b}$ is government transfers to each public sector employee when employed, $\bar{G}_{t}^{t r, u}$ is government transfers to each public sector employee when unemployed and $\bar{y}_{t}^{b}$ is a private unemployment insurance whose price is $\mu_{t}^{b}$.

Thus, in each period, each public employee maximizes expected utility:

$$
q\left[\mu_{1} \log c_{t}^{b, e}+\mu_{2} \log \left(1-h e_{t}^{b}\right)+\left(1-\mu_{1}-\mu_{2}\right) \log Y_{t}^{g}\right]+(1-q)\left[\mu_{1} \log c_{t}^{b, u}+\left(1-\mu_{1}-\mu_{2}\right) \log Y_{t}^{g}\right]
$$

subject to the single expected budget constraint:

$$
q\left(1+\tau_{t}^{c}\right) c_{t}^{b, e}+(1-q)\left(1+\tau_{t}^{c}\right) c_{t}^{b, u}+\mu_{t}^{b} \bar{y}_{t}^{b}=q\left(1-\tau_{t}^{l}\right) w_{t}^{g} e_{t}^{b} h+q \bar{G}_{t}^{t r, b}+(1-q) \bar{y}_{t}^{b}+(1-q) \bar{G}_{t}^{t r, u}
$$


Each $b$ chooses $\left\{c_{t}^{b, e}, c_{t}^{b, u}, e_{t}^{b}, \bar{y}_{t}^{b}\right\}_{t=0}^{\infty}$ acting competitively. The first-order conditions include the budget constraint in (24) and:

$c_{t}^{b, e}=c_{t}^{b, u}=c_{t}^{b}$

$\frac{\mu_{2}}{\left(1-h e_{t}^{b}\right)}=\frac{\mu_{1}\left(1-\tau_{t}^{l}\right) w_{t}^{g}}{\left(1+\tau_{t}^{c}\right) c_{t}^{b, e}}$

$\mu_{t}^{b}=1-q$

If we combine these first-order conditions, the labor supply condition (25b) can be rewritten as:

$\frac{\mu_{2}}{\left(1-h e_{t}^{b}\right)}=\frac{\mu_{1}\left(1-\tau_{t}^{l}\right) w_{t}^{g}}{q\left(1-\tau_{t}^{l}\right) w_{t}^{g} h e_{t}^{b}+q \bar{G}_{t}^{t r, b}+(1-q) \bar{G}_{t}^{t r, u}}$

which is like (11) above for the private worker and can give (16) as a special case.

The new DCE system, as well as the associated new market-clearing conditions, is presented in the Appendix (see Appendices 3 and 4).

\subsection{Steady state solutions of the reformed economies}

In this subsection, we provide steady state solutions under the reforms listed in Table 3. The parameterization is as in Table 1 except that now $q=\varphi=0.9<1$. The solution, under each type of reform, is reported in Table 4, where in the first column - for expositional convenience - we also repeat the status quo solution of Table 2. Notice that some ratios remain unchanged across regimes; this happens because of the functional forms used in the numerical solution but it is not important to the main results.

Table 4 around here

Steady state solutions

We start with Reform no. 1, as defined in Table 3, and compare it to the status quo. On the positive side, Reform no. 1 improves work incentives ( $e^{b}$ rises) in the public sector and enhances private output. On the negative side, public output and per 
capita welfare all fall. But all these effects are marginal in magnitude (for instance, per capita output increases by less than $0.5 \%$ ) so we are inclined to claim that the introduction of job insecurity in the public sector does not appear by itself to generate substantial social benefits.

Under Reform no. 2, as defined in Table 3, work incentives in the public sector clearly deteriorate ( $e^{b}$ falls a lot) and this is damaging for public sector output. This happens mainly because the resulting fall in wages in the public sector further damages the work incentive of public employees. Public sector efficiency rises (although public output decreases) but this happens only because public wages have fallen substantially. On the other hand, per capita output increases but again the change is quantitatively weak (less than $1 \%$ ). Thus, as with job insecurity, the attempt to link public wages to productivity in the public sector cannot by itself lead to social benefits.

Reform no. 3, as defined in Table 3, is different. Now, work incentives in the public sector clearly improve ( $e^{b}$ rises a lot) and, at same time, private output, public output and per capita utility all rise. In particular, private and public output increase by more than $4 \%$ and $30 \%$ respectively. The same applies to public sector efficiency which rises substantially vis-à-vis the status quo. Notice that a larger tax base allows a cut in the labour tax rate that further stimulates the aggregate economy. On the negative side, public employees get worse off; public wages and transfers allocated to public employees both fall, so their net income and consumption also fall.

Reform no. 4 (which is a combined mix of Reforms 1, 2 and 3) is like Reform no. 3 both qualitatively and quantitatively, indicating that the main results are driven by Reform no. 3.

Therefore, taking stock of results so far, the key reform is no. 3. It is thus good for the general interest to equalize the ratio of non-labor transfers to the wage rate in the two sectors, $\frac{\bar{G}_{t}^{t r, w}}{w_{t}^{w}} \neq \frac{\bar{G}_{t}^{t r, b}}{w_{t}^{g}}$, and, at the same time, to use the efficiency savings enjoyed by the switch to a more efficient economy - to cut labor taxes. The latter creates a second round of social benefits. The problem, as it usually happens, is that this reform is not a free lunch: although per capita private and public output, public sector efficiency and per capita welfare all rise vis-à-vis the status quo, public 
employees get impoverished by the fall in their net income and get worse off relative to the status quo.

It is then natural to ask: is it possible to find a mix of policy reforms that are not only socially beneficial, but also do not hurt the net income and the consumption level of public employees? Since the above reforms were accompanied by a substantial fall in public wages that impoverished public employees, we now search for a mix that combines the key reform (Reform no. 3) with a policy that keeps the wage rate in the public sector above a minimum value. For instance, in Reform no. 5, we replace the condition $w_{t}^{g}=\frac{(1-\theta) Y_{t}^{g}}{L_{t}^{g}}$ with the condition $w_{t}^{g}=w_{t}^{p}$ (Gomes, 2014, also links public wages to private wages in a reformed economy). In all other aspects, Reform no. 5 is like Reform no. 4. Then, the results reported in the last column of Table 4 imply that, in this case, the increase in the net income and consumption of capitalists and private workers is not accompanied by a big decrease in the net income and consumption of public employees as it happened under Reforms 3 and 4. Public employees may be worse off in terms of utility relative to the status quo but since - by construction - they enjoy the same wage rate as their private counterparts, $w_{t}^{g}=w_{t}^{p}$, the decrease in utility is mainly explained by the fact that they now work harder. Private output, public output as well as per capita welfare all rise relative to the status quo, although now these rises are smaller than in Reforms 3 and 4. For instance, in Reform no. 5, private output increases by about 2.7\%, which is smaller than the increase by more than $6 \%$ obtained in Reform no. 4 . On the negative side, since now public wages are relatively high, public sector efficiency slightly falls relative to the status quo. This is unavoidable cost of social protection. In sum, we cannot avoid the standard tradeoff between efficiency and equity. A social value judgment has to be made.

\subsection{Transition results as we travel to the reformed economy}

We next study what happens when we depart from the pre-reform status quo economy and travel towards a new long-run of a reformed economy. ${ }^{14}$

\footnotetext{
${ }^{14}$ We work as follows. We first solve and compare long-run equilibria with and without reforms. We then check that, when log-linearized around its steady state solution, each model economy is saddlepath stable. This is for each type of reform and each method of public financing studied. In turn, setting, as initial conditions for the state variables, their values from the steady state solution of the
} 
To save on space, we focus on the case in which the economy travels to the long-run equilibrium that corresponds to Reform no. 5, since the latter is a combination of all other reforms. As said above, along the transition, public debt is the residually determined public financing variable. Results for the discounted lifetime utility of the three agents, namely, capitalists, public employees and private workers, denoted as $U^{k}, U^{b}$ and $U^{w}$ respectively, as well as per capita discounted lifetime utility, denoted as $U$, are reported in Table 5 .

Table 5 around here Discounted lifetime utility

Inspection of Table 5 reveals that, as it was also the case when we compared steady state solutions, capitalists and private sector employees, as well as the aggregate economy, benefit from the adoption of Reform no. 5. On the other hand, this Reform again hurts those working in the public sector. The latter are now worse off relative to the pre-reform economy. In particular, the last column of Table 5 indicates that public sector employees should receive a consumption subsidy of $25 \%$ in order to be indifferent between the pre-reform and the reformed economy. On the other hand, capitalists, private sector employees and the overall economy enjoy a consumption benefit of $17 \%, 20 \%$ and $10 \%$ respectively from a switch to the reformed economy. Details on the calculation of these consumption equivalents, denoted as $\xi$ in Table 5, are in Appendix 7.

\section{Conclusions, political economy issues and extensions}

In this paper, we searched for policy reforms that can strengthen the incentive to work in the public sector. Using a general equilibrium setup with heterogeneous agents and a potential conflict of interests, we showed that the adoption of specific reforms - the main feature of which was the establishment of parity between employment conditions in the public sector and employment conditions in the private sector -

status quo economy, we compute the equilibrium transition path of each reformed economy and in turn calculate the associated discounted lifetime utilities of the three types of households as well as the resulting per capita lifetime utility. These utilities are finally compared to their associated values if we had remained in the status quo economy forever. Recall that the model is deterministic so that the only source of transition dynamics is policy reforms. 
improve work incentives in the public sector, as well as benefit the aggregate economy, but at the cost of making the existing public employees worse off.

This type of work can be extended in various ways. For instance, we can add imperfect competition in product markets, as well as, trade union and rent seeking behavior on the part of public employees. Another key issue is the political feasibility of reforms (see Drazen, 2000, chapter 13). Here, we just compared the status quo to various reforms by sidestepping the issue of whether reforms are feasible politically. But a natural question to ask is: If some reforms can lift the society out of the status quo trap, meaning that they can make the majority better off, why don't we observe them in practice? In a direct democracy, it would be puzzling why socially beneficial reforms are not adopted or are adopted only with delay. In our model, for instance, if capitalists and private workers have the majority vote, such reforms should be enacted as fully and as quickly as possible.

Several interpretations, and therefore model extensions, can come to mind. For instance, as Alesina (1999) points out, in most industrial countries nowadays, a bigger and bigger fraction of the population derives its main source of income from the public sector. Here, we modeled the behavior of public employees only. But there are also pensioners, unemployed people, private firms, etc, who also rely on the government. Jointly with public employees, these groups can form a majority reluctant to reforms. This means that our model could be extended to include these other groups. Another interpretation, and therefore model extension, could be that democracies are not perfect, meaning that the one-man-one-vote rule does not always apply. In representative democracy systems, minorities can use their political or money power to block socially beneficial reforms and maintain the status quo, even if the latter hurts the majority of the society (see Acemoglu, 2009, chapter 22, for why inefficient institutions emerge and persist and Rajan, 2009, for reform paralysis). Typically, this happens through the political system. In the context of our model, even if public employees are few in number, they may have enough political power to block reforms. This means that our model could be extended to account for the (mutually beneficial) interaction between interest groups and policymakers at the top of the government hierarchy, and how this interaction ensures the preservation of the status quo. We leave these extensions for future work. 


\section{References}

Acemoglu D. (2009): Introduction to Modern Economic Growth. Princeton University Press, Princeton.

Acemoglu D. and T. Verdier (2000): The choice between market failures and corruption, American Economic Review, 90, 194-211.

Afonso A., L. Schuknecht and V. Tanzi (2005): Public sector efficiency: An international comparison, Public Choice, 123, 321-347.

Alesina A. (1999): Too large and too small governments, in Economic Policy and Equity, edited by V. Tanzi, K. Chu and S. Gupta, International Monetary Fund, Washington, D.C.

Alesina A. and F. Giavazzi (2006): The Future of Europe: Reform or Decline. MIT Press, Cambridge, Mass.

Angelopoulos K., A. Philippopoulos and M. Tsionas (2008): Does public sector efficiency matter? Revisiting the relation between fiscal size and economic growth in a world sample, Public Choice, 137, 245-278.

Ardagna S. (2007): Fiscal policy in unionized labor markets, Journal of Economic Dynamics and Control, 31, 1498-1534.

Atkinson A. and J. Stiglitz (1980): Lectures on Public Economics. McGraw Hill, London.

Blank R. (1994): Public sector growth and labor flexibility: The US vs the UK. In Social Protection vs Economic Flexibility: Is there a tradeoff?, edited by R. Blank, University of Chicago Press.

Buelens M. and H. van den Broeck (2007): An analysis of differences in work motivation between public and private sector organizations, Public Administration Review, 67, 65-74.

Cavalcanti T. and M. R. Dos Santos (2014): (Mis)Allocation effects of an overpaid public sector, mimeo.

Chari V.V., L. Christiano and P. Kehoe (1995): Policy analysis in business cycle model. In Frontiers of Business Cycle Research, edited by T. Cooley, Princeton University Press.

Cole H. and L. Ohanian (2004): New Deal policies and the persistence of the Great Depression: A general equilibrium analysis, Journal of Political Economy, 112, 779816. 
de Castro F., M. Salto and H. Steiner (2013): The gap between public and private wages: new evidence for the EU, Economic Papers, no. 508, European Commission, Brussels.

Diamond P. and E. Saez (2011): The case for a progressive tax: From basic research to policy recommendations. CESifo Working Paper, no. 3548, CESifo, Munich.

Drazen A. (2000): Political Economy in Macroeconomics. Princeton University Press.

Economides G., D. Papageorgiou, A. Philippopoulos and V. Vassilatos (2013): Smaller public sectors in the euro area: aggregate and distributional implications, CESifo Economic Studies, 59, 536-558.

Economides G., A. Philippopoulos and V. Vassilatos (2014): Public, or private, providers of public goods? A dynamic general equilibrium study, European Journal of Political Economy, 36, 202-327.

Fang L. and R. Rogerson (2011): Product market regulation and market work: A benchmark analysis, American Economic Journal: Macroeconomics, 3, 163-188.

Gomes P. (2014): Reforming the public sector's wage policy, mimeo.

Guo J.T. and K. Lansing (1999): Optimal taxation of capital income with imperfectly competitive product markets, Journal of Economic Dynamics and Control, 23, 967995.

Hansen G. D. (1985): Indivisible labor and the business cycle, Journal of Monetary Economics, 16, 309-327.

Hassler J., P. Krusell, K. Storesletten and F. Zilibotti (2005): The dynamics of government, Journal of Monetary Economics, 52, 1331-1358.

Hassler J., K. Storesletten and F. Zilibotti (2007): Democratic public good provision, Journal of Economic Theory, 133, 127-151.

Hillman A. (2009): Public Finance and Public Policy. Cambridge University Press, second edition, Cambridge.

Hornstein A., P. Krusell and G. Violante (2005): The effects of technical change on labor market inequalities, in Handbook of Economic Growth, volume 1B, edited by P. Aghion and S. Durlauf, North-Holland, Amsterdam.

Judd K. (1985): Redistributive taxation in a simple perfect foresight model, Journal of Public Economics, 28, 59-83.

King R. and S. Rebelo (1999): Resuscitating real business cycles. In Handbook of Macroeconomics, volume 1B, edited by J. Taylor and M. Woodford, North-Holland, Amsterdam. 
Krueger D. and F. Perri (2011): Public versus private risk sharing, Journal of Economic Theory, 146, 920-956.

Linnemann L. (2009): Macroeconomic effects of shocks to public employment, Journal of Macroeconomics, 31, 252-267.

Mendoza E. and L. Tesar (2005): Why hasn't tax competition triggered a race to the bottom? Some quantitative lessons from the EU, Journal of Monetary Economics, 52, 163-204.

Munnell A., J.P. Aubry, J. Hurwitz and L. Quinby (2011): Comparing compensation: state-local versus private sector workers, Center for Retirement Research at Boston University, Boston University, Working Paper, no. 20.

Pappa E. (2009): The effects of fiscal shocks on employment and the real wage, International Economic Review, 50, 217-244.

Pestieau P. (2007): Assessing the performance of the public sector, CREPP Working Paper, no. 2007/03, University of Liege.

Rajan R. (2009): Rent preservation and the persistence of underdevelopment, American Economic Journal: Macroeconomics, 1, 178-218.

Rogerson R. (1988): Indivisible labor, lotteries and equilibrium, Journal of Monetary Economics, 21, 3-16.

Sørensen P. B. (2014): Reforming public service provision: What have we learnt?, mimeo.

Wren-Lewis S. (2010): Macroeconomic policy in light of the credit crunch: the return of counter-cyclical fiscal policy? Oxford Review of Economic Policy, 26, 71-68. 


\section{APPENDIX}

\section{Appendix 1: Turnover in the public sector}

The data source is Eurostat. Data are yearly and cover a maximum time span from 1996 to 2012. The countries included in the data set are Austria, Belgium, Cyprus, Czech Republic, Denmark, Estonia, Finland, France, Germany, Greece, Hungary, Ireland, Italy, Latvia, Lithuania, Luxembourg, Malta, Netherlands, Poland, Portugal, Slovenia, Slovak Republic, Spain, Sweden, UK, US and Japan. Employment in the public sector corresponds to the number of employees in public administration, defense, education, human health and social work activities. Employment in the private sector is computed as total employees minus employment in the public sector. Finally, turnover in the public sector is defined as the standard deviation of employment in the public sector relative to the standard deviation of employment in the private sector. A value of this ratio less than 1 implies that job insecurity in the public sector is lower than job insecurity in the private sector.

\begin{tabular}{|c|c|}
\hline Country & Turnover ratio \\
\hline Austria & 0.509398 \\
\hline Belgium & 1.034886 \\
\hline Cyprus & 0.274710 \\
\hline Estonia & 0.286157 \\
\hline Finland & 0.415131 \\
\hline France & 0.294902 \\
\hline Germany & 0.545764 \\
\hline Greece & 0.485933 \\
\hline Hungary & 0.265679 \\
\hline Ireland & 0.639663 \\
\hline Italy & 0.063845 \\
\hline Latvia & 0.125081 \\
\hline Lithuania & 0.179500 \\
\hline Luxembourg & 0.287126 \\
\hline Malta & 0.535983 \\
\hline Netherlands & 0.864326 \\
\hline Poland & 0.188547 \\
\hline Portugal & 0.418393 \\
\hline Slovenia & 0.612587 \\
\hline Slovak Republic & 0.111292 \\
\hline Spain & 0.293899 \\
\hline Sweden & 0.309194 \\
\hline UK & 1.238642 \\
\hline Denmark & 0.318628 \\
\hline Czech Republic & 0.149596 \\
\hline US & 1.054764 \\
\hline Japan & 0.958346 \\
\hline
\end{tabular}

Source: Eurostat. 


\section{Appendix 2: Public spending categories expressed as shares of output}

(a) $G_{t}^{g}=s_{t}^{g} N_{t}^{k} y_{t}^{f}$ so that $\bar{G}_{t}^{g}=\frac{G_{t}^{g}}{N_{t}}=s_{t}^{g} v_{t}^{k} y_{t}^{f}$.

(b) $\quad G_{t}^{w}=s_{t}^{w} N_{t}^{k} y_{t}^{f} \quad$ so that $\quad \bar{G}_{t}^{w}=\frac{G_{t}^{w}}{N_{t}}=s_{t}^{w} v_{t}^{k} y_{t}^{f}$. In turn, since $G_{t}^{w}=w_{t}^{g} L_{t}^{g}=w_{t}^{g} N_{t}^{b} q e_{t}^{b} h, \bar{G}_{t}^{w}=s_{t}^{w} v_{t}^{k} y_{t}^{f}=w_{t}^{g} v_{t}^{b} q e_{t}^{b} h$ or $w_{t}^{g}=\frac{s_{t}^{w} v_{t}^{k} y_{t}^{f}}{v_{t}^{b} q e_{t}^{b} h}$. Thus, the public wage rate, $w_{t}^{g}$, is determined by the related "market-clearing" condition (namely, that total spending on the public wage bill, $G_{t}^{w}$, equals the wage rate multiplied by total effective labor in the public sector), when the public wage bill as share of GDP, $s_{t}^{w}$, is set as in the data.

(c) $G_{t}^{t r, k}=s_{t}^{t r, k} N_{t}^{k} y_{t}^{f}$, so that $\bar{G}_{t}^{t r, k}=\frac{G_{t}^{t r, k}}{N_{t}^{k}}=s_{t}^{t r, k} y_{t}^{f}$.

(d) $G_{t}^{t r, w}=s_{t}^{t r, w} N_{t}^{k} y_{t}^{f}$, so that $\bar{G}_{t}^{t r, w} \equiv \frac{G_{t}^{t r, w}}{\varphi N_{t}^{w}}=s_{t}^{t r, w} \frac{v_{t}^{k}}{\varphi v_{t}^{w}} y_{t}^{f}$.

(e) $G_{t}^{t r, b}=s_{t}^{t r, b} N_{t}^{k} y_{t}^{f}$ so that $\bar{G}_{t}^{t r, b}=\frac{G_{t}^{t r, b}}{q N_{t}^{b}}=s_{t}^{t r, b} \frac{v_{t}^{k}}{q v_{t}^{b}} y_{t}^{f}$ where $s_{t}^{t r, k}+s_{t}^{t r, w}+s_{t}^{t r, b} \equiv s_{t}^{t r}$, and where $s_{t}^{t r}$ is the share of transfers in the data.

(f) $G_{t}^{t r, u}=s_{t}^{t r, u} N_{t}^{k} y_{t}^{f}$ so that $\bar{G}_{t}^{t r, u}=\frac{G_{t}^{t r, u}}{(1-\phi) N_{t}^{w}+(1-q) N_{t}^{b}}=s_{t}^{t r, u} \frac{v_{t}^{k}}{(1-\phi) v_{t}^{w}+(1-q) v_{t}^{b}} y_{t}^{f}$.

\section{Appendix 3: The insurance company}

The insurance company maximizes period-by-period profits by choosing a supply of unemployment insurance, denoted as $I$. Thus, it maximizes $\mu_{t}^{w} I-(1-\varphi) I$. Since $\mu_{t}^{w}=(1-\varphi)$ from the worker's optimization problem, the insurance company is at its break-even point.

\section{Appendix 4: Market-clearing conditions}

The equations below are the market-clearing conditions in the general case in which there is job uncertainty in both the private and the public sector. The market-clearing 
conditions of the status quo model, in which there is job uncertainty in the private sector only, follows as a special case if set $q_{t}=1$.

The market-clearing conditions in the labor markets are:

$N_{t}^{f} e_{t}^{f, k}=N_{t}^{k} e_{t}^{f, k}=N_{t}^{k} e_{t}^{k} h \Rightarrow e_{t}^{f, k}=e_{t}^{k} h$

$N_{t}^{f} e_{t}^{f, w}=N_{t}^{k} e_{t}^{f, w}=\varphi N_{t}^{w} e_{t}^{w} h \Rightarrow e_{t}^{f, w}=\varphi \frac{v_{t}^{w}}{v_{t}^{k}} e_{t}^{w} h$

$L_{t}^{g}=q N_{t}^{b} e_{t}^{b} h$

The market-clearing conditions in capital, bond and dividend markets are respectively:

$N_{t}^{f} k_{t}^{f}=N_{t}^{k} k_{t}^{k} \Rightarrow k_{t}^{f}=k_{t}^{k}$

$N_{t}^{k} b_{t}^{k}=B_{t}$

$N_{t}^{f} \pi_{t}^{f}=N_{t}^{k} \pi_{t}^{k} \Rightarrow \pi_{t}^{f}=\pi_{t}^{k}$

Finally, the market-clearing condition in the goods market (this is also the economy's resource constraint) is:

$N_{t}^{k} c_{t}^{k}+N_{t}^{w} c_{t}^{w}+N_{t}^{b} c_{t}^{b}+N_{t}^{k}\left(k_{t+1}^{k}-(1-\delta) k_{t}^{k}\right)+G_{t}^{g}=N_{t}^{f} y_{t}^{f}=N_{t}^{k} y_{t}^{f}$

\section{Appendix 5: Decentralized Competitive Equilibrium}

The system below summarizes the DCE in the general case in which there is job uncertainty in both the private and the public sector. The DCE of the status quo model, in which there is job uncertainty in the private sector only, follows as a special case if set $q_{t}=1$.

Capitalists:

$$
\begin{aligned}
& \frac{\mu_{2}}{\left(1-h e_{t}^{k}\right)}=\frac{\mu_{1}\left(1-\tau_{t}^{l}\right) w_{t}^{k}}{\left(1+\tau_{t}^{c}\right) c_{t}^{k}} \\
& \left(1+\tau_{t+1}^{c}\right) c_{t+1}^{k}=\beta\left(1+\tau_{t}^{c}\right) c_{t}^{k}\left[1-\delta+\left(1-\tau_{t+1}^{k}\right) r_{t+1}\right]
\end{aligned}
$$


$\left(1+\tau_{t+1}^{c}\right) c_{t+1}^{k}=\beta\left(1+\tau_{t}^{c}\right) c_{t}^{k}\left(1+i_{t+1}\right)$

Private workers:

$\left(1+\tau_{t}^{c}\right) c_{t}^{w}=\varphi_{t}\left(1-\tau_{t}^{l}\right) w_{t}^{w} e_{t}^{w} h+\varphi_{t} \bar{G}_{t}^{t r, w}+\left(1-\varphi_{t}\right) \bar{G}_{t}^{t r, u}$

$\frac{\mu_{2}}{\left(1-h e_{t}^{w}\right)}=\frac{\mu_{1}\left(1-\tau_{t}^{l}\right) w_{t}^{w}}{\varphi\left(1-\tau_{t}^{l}\right) w_{t}^{w} h e_{t}^{w}+\varphi \bar{G}_{t}^{t r, w}+(1-\varphi) \bar{G}_{t}^{t r, u}}$

where we use $\bar{G}_{t}^{t r, w}=s_{t}^{t r, w} \frac{v_{t}^{k}}{\varphi_{t} v_{t}^{w}} y_{t}^{f}$ and $\bar{G}_{t}^{r, u}=s_{t}^{t r, u} \frac{v_{t}^{k}}{\left(1-\varphi_{t}\right) v_{t}^{w}+\left(1-q_{t}\right) v_{t}^{b}} y_{t}^{f}$

Public employees:

$$
\begin{aligned}
& \left(1+\tau_{t}^{c}\right) c_{t}^{b}=q_{t}\left(1-\tau_{t}^{l}\right) w_{t}^{g} e_{t}^{b} h+q_{t} \bar{G}_{t}^{t r, b}+\left(1-q_{t}\right) \bar{G}_{t}^{t r, u} \\
& \frac{\mu_{2}}{\left(1-h e_{t}^{b}\right)}=\frac{\mu_{1}\left(1-\tau_{t}^{l}\right) w_{t}^{g}}{q\left(1-\tau_{t}^{l}\right) w_{t}^{g} h e_{t}^{b}+q \bar{G}_{t}^{t r, b}+(1-q) \bar{G}_{t}^{t r, u}}
\end{aligned}
$$

where we use $\bar{G}_{t}^{t r, b}=s_{t}^{t r, b} \frac{v_{t}^{k}}{q_{t} v_{t}^{b}} y_{t}^{f}$ and $\bar{G}_{t}^{r, u}=s_{t}^{t r, u} \frac{v_{t}^{k}}{\left(1-\varphi_{t}\right) v_{t}^{w}+\left(1-q_{t}\right) \nu_{t}^{b}} y_{t}^{f}$.

Other equations:

$$
\begin{aligned}
& v_{t}^{k} y_{t}^{f}=A\left(v_{t}^{k} k_{t}^{k}\right)^{\alpha_{1}}\left(A^{k} v_{t}^{k} e_{t}^{k} h+A^{w} \varphi_{t} v_{t}^{w} e_{t}^{w} h\right)^{\alpha_{2}}\left(\bar{Y}_{t}^{g}\right)^{1-\alpha_{1}-\alpha_{2}} \\
& r_{t}=\alpha_{1} \frac{y_{t}^{f}}{k_{t}^{k}} \\
& w_{t}^{w}=\alpha_{2} A^{w} \frac{v_{t}^{k} y_{t}^{f}}{\left(A^{k} v_{t}^{k} e_{t}^{k} h+A^{w} \varphi_{t} v_{t}^{w} e_{t}^{w} h\right)} \\
& w_{t}^{k}=\alpha_{2} A^{k} \frac{v_{t}^{k} y_{t}^{f}}{\left(A^{k} v_{t}^{k} e_{t}^{k} h+A^{w} \varphi_{t} v_{t}^{w} e_{t}^{w} h\right)} \\
& \left(s_{t}^{g}+s_{t}^{w}+s_{t}^{t r, k}+s_{t}^{t r, w}+s_{t}^{t r, b}+s_{t}^{t r, u}\right) v_{t}^{k} y_{t}^{f}+\left(1+i_{t}\right) b_{t}=b_{t+1}+ \\
& +\tau_{t}^{c}\left(v_{t}^{k} c_{t}^{k}+v_{t}^{w} c_{t}^{w}+v_{t}^{b} c_{t}^{b}\right)+\tau_{t}^{k} v_{t}^{k}\left(r_{t} k_{t}^{k}+\pi_{t}^{k}\right)+\tau_{t}^{l}\left(v_{t}^{k} w_{t}^{k} e_{t}^{k} h+\varphi_{t} v_{t}^{w} w_{t}^{w} e_{t}^{w} h+q_{t} v_{t}^{b} w_{t}^{g} e_{t}^{b} h\right) \\
& \bar{Y}_{t}^{g} \equiv y_{t}^{g}=A\left(s_{t}^{g} v_{t}^{k} y_{t}^{f}\right)^{\theta}\left(q_{t} v_{t}^{b} e_{t}^{b} h\right)^{1-\theta} \\
& v_{t}^{k} c_{t}^{k}+v_{t}^{w} c_{t}^{w}+v_{t}^{b} c_{t}^{b}+v_{t}^{k}\left(k_{t+1}^{k}-(1-\delta) k_{t}^{k}\right)+s_{t}^{g} v_{t}^{k} y_{t}^{f}=v_{t}^{k} y_{t}^{f} \\
& w_{t}^{g}=\frac{s_{t}^{w} v_{t}^{k} y_{t}^{f}}{v_{t}^{b} q_{t} e_{t}^{b} h}
\end{aligned}
$$


$\pi_{t}^{k}=\left(1-\alpha_{1}-\alpha_{2}\right) y_{t}^{f}$

We thus have a system of 16 equations in 16 endogenous variables.

\section{Appendix 6: Measure of productive efficiency}

Public sector efficiency is defined as public output as a share of public sector expenditure that the government allocates to achieve this particular output. Thus,

$\operatorname{PubSE}_{t} \equiv \frac{Y_{t}^{g}}{G_{t}^{g}+G_{t}^{w}}=\frac{y_{t}^{g}}{s_{t}^{g} v_{t}^{k} y_{t}^{f}+s_{t}^{w} v_{t}^{k} y_{t}^{f}}$

where $Y_{t}^{g}$ is "imputed" from the model solution.

Similarly, we measure private sector efficiency. Thus,

$$
\operatorname{PrivSE} E_{t} \equiv \frac{y_{t}^{f}}{r_{t} k_{t}^{k}+w_{t}^{p}\left[e_{t}^{k}+\varphi_{t} \frac{v_{t}^{w}}{v_{t}^{k}} e_{t}^{w}\right]}
$$

\section{Appendix 7: Comparison of lifetime utility under reforms}

Status quo economy (denoted by superscript SQ)

Expected discounted lifetime utility for the capitalist, the private worker and the public employee are defined respectively:

$$
\begin{aligned}
U^{k, S Q} & \equiv \frac{\mu_{1} \log c^{k, S Q}+\mu_{2} \log \left(1-h e^{k, S Q}\right)+\left(1-\mu_{1}-\mu_{2}\right) \log \bar{Y}^{g, S Q}}{1-\beta} \\
U^{w, S Q} & \equiv \frac{\mu_{1} \log c^{w, S Q}+\varphi \mu_{2} \log \left(1-h e^{w, S Q}\right)+\left(1-\mu_{1}-\mu_{2}\right) \log \bar{Y}^{g, S Q}}{1-\beta} \\
U^{b, S Q} & \equiv \frac{\mu_{1} \log c^{b, S Q}+\mu_{2} \log \left(1-h e^{b, S Q}\right)+\left(1-\mu_{1}-\mu_{2}\right) \log \bar{Y}^{g, S Q}}{1-\beta}
\end{aligned}
$$

where all variables above are set at their steady state values (if there neither reforms nor shocks, there are no transition dynamics).

Reformed economy (denoted by superscript $R$ )

Expected discounted lifetime utility for the capitalist, the private worker and the public employee are defined respectively: 


$$
\begin{aligned}
U^{k, R} & \equiv \sum_{t=0}^{\infty} \beta^{t}\left[\mu_{1} \log c_{t}^{k, R}+\mu_{2} \log \left(1-h e_{t}^{k, R}\right)+\left(1-\mu_{1}-\mu_{2}\right) \log \bar{Y}_{t}^{g, R}\right] \\
U^{w, R} & \equiv \sum_{t=0}^{\infty} \beta^{t}\left[\mu_{1} \log c_{t}^{w, R}+\varphi \mu_{2} \log \left(1-h e_{t}^{w, R}\right)+\left(1-\mu_{1}-\mu_{2}\right) \log \bar{Y}_{t}^{g, R}\right] \\
U^{b, R} & \equiv \sum_{t=0}^{\infty} \beta^{t}\left[\mu_{1} \log c_{t}^{b, R}+q \mu_{2} \log \left(1-h e_{t}^{b, R}\right)+\left(1-\mu_{1}-\mu_{2}\right) \log \bar{Y}_{t}^{g, R}\right]
\end{aligned}
$$

where the time-paths of all variables above are as in their reformed economy (now there are transition dynamics driven by policy reforms).

\section{Welfare comparison of the two economies}

Starting with capitalists, we solve for a consumption subsidy, defined as $\xi_{k}$, that makes them indifferent between the two regimes. Thus,

$$
\begin{gathered}
\frac{\mu_{1} \log \left\{\left(1+\xi_{k}\right) c^{k, \mathrm{SQ}}\right\}+\mu_{2} \log \left(1-h e^{k, \mathrm{SQ}}\right)+\left(1-\mu_{1}-\mu_{2}\right) \log \bar{Y}^{g, \mathrm{SQ}}}{1-\beta}= \\
=\sum_{t=0}^{\infty} \beta^{t}\left[\mu_{1} \log c_{t}^{k, R}+\mu_{2} \log \left(1-h e_{t}^{k, R}\right)+\left(1-\mu_{1}-\mu_{2}\right) \log \bar{Y}_{t}^{g, R}\right]
\end{gathered}
$$

or approximately:

$$
\xi_{k} \cong \frac{(1-\beta)\left(U^{k, R}-U^{k, \mathrm{SQ}}\right)}{\mu_{1}}
$$

Similarly, we have $\xi_{w} \cong \frac{(1-\beta)\left(U^{w, R}-U^{w, S Q}\right)}{\mu_{1}}$ and $\xi_{b} \cong \frac{(1-\beta)\left(U^{b, R}-U^{b, \mathrm{SQ}}\right)}{\mu_{1}}$ for the other two agents. 
Table 1: Baseline parameterization

\begin{tabular}{|c|c|c|}
\hline $\begin{array}{c}\text { Parameters } \\
\text { and policy } \\
\text { instrument } \\
s\end{array}$ & Description & Value \\
\hline$\alpha_{1}$ & Share of capital in private production & 0.33 \\
\hline$\alpha_{2}$ & Share of labor in private production & 0.64 \\
\hline $1-\theta$ & Share of public employment in public production & 0.569 \\
\hline$\delta$ & Capital depreciation rate & 0.05 \\
\hline$\beta$ & Rate of time preference & 0.99 \\
\hline$\mu_{1}$ & Preference parameter on private consumption in utility & 0.3 \\
\hline$\mu_{2}$ & Preference parameter on leisure in utility & 0.6 \\
\hline$S^{w}$ & Public wage payments as share of GDP (data) & 0.132 \\
\hline$S^{g}$ & Public purchases as share of GDP (data) & 0.10 \\
\hline$S^{t r}$ & Public transfers as share of GDP (data) & 0.2170 \\
\hline$S^{t r, k}$ & Public transfers as share of GDP to capitalists (adjusted) & 0.0201 \\
\hline$s^{t r, w}$ & Public transfers as share of GDP to private workers (adjusted) & 0.0865 \\
\hline$s^{t r, b}$ & Public transfers as share of GDP to public sector employees (adjusted) & 0.1104 \\
\hline$s^{t r, u}$ & Public transfers as share of GDP to unemployed persons (data) & 0.0110 \\
\hline$\tau^{c}$ & Tax rate on consumption (data) & 0.1938 \\
\hline$\tau^{k}$ & Tax rate on capital income (data) & 0.2903 \\
\hline$\tau^{l}$ & Tax rate on labor (data) & 0.3780 \\
\hline$B / Y$ & Public debt as a share of GDP (data) & 0.9 \\
\hline$v^{k}$ & Capitalists as share of population (data) & 0.1480 \\
\hline$v^{w}$ & Workers as share of population (data) & 0.6370 \\
\hline$v^{b}$ & Public employees as share of population (data) & 0.2150 \\
\hline $1-\varphi$ & Probability of unemployment for private workers (set) & 0.10 \\
\hline $1-q$ & Probability of unemployment for public sector employees (set) & 0 and 0.10 \\
\hline$A$ & Long-run TFP (set) & 1 \\
\hline
\end{tabular}

Notes: Regarding fiscal policy variables, we use data averages of the Eurozone over 20002012 (data source: Eurostat). 
Table 2: Steady state solution of the status quo economy

\begin{tabular}{|c|c|}
\hline Variable & Status Quo \\
\hline$c^{k}$ & 0.290 \\
\hline$e^{k}$ & 0.154 \\
\hline$k^{k}$ & 9.547 \\
\hline$c^{w}$ & 0.237 \\
\hline$e^{w}$ & 0.309 \\
\hline$c^{b}$ & 0.287 \\
\hline$e^{b}$ & 0.186 \\
\hline$w^{g} / w^{p}$ & 1.03 \\
\hline$y$ & 0.363 \\
\hline$y^{g}$ & 0.038 \\
\hline$c / y$ & 0.705 \\
\hline$k / y$ & 3.897 \\
\hline$b / y$ & 0.9 \\
\hline$\tau^{l}$ & 0.295 \\
\hline$s^{w}$ & 0.132 \\
\hline$s^{t r, b}$ & 0.1104 \\
\hline$u^{k}$ & -0.798 \\
\hline$u^{w}$ & -0.957 \\
\hline$u^{b}$ & -0.824 \\
\hline$u$ & -0.905 \\
\hline PubSE & 0.456 \\
\hline PrivSE & 1.031 \\
\hline PubSE / PrivSE & 0.442 \\
\hline
\end{tabular}

Notes: (i) We use the baseline parameterization in Table 1. (ii) $u=v^{p} u^{p}+v^{b} u^{b}$ (the same formula is used for all per capita quantities). 
Table 3: Description of policy reforms

\begin{tabular}{|c|c|}
\hline Reform & Description \\
\hline 1 & decrease in $q$ and $s^{w}$ (by $\left.10 \%\right)$ \\
\hline 2 & $w_{g}=$ marginal product of $L^{g}$ \\
\hline 3 & $\bar{G}^{t r, b} / w_{g}=\bar{G}^{t r, w} / w_{p}$ \\
\hline 4 & $\bar{G}^{t r, b} / w_{g}=\bar{G}^{t r, w} / w_{p}, w_{g}=$ marginal product of $L^{g}$, decrease in $q$ \\
\hline 5 & $\bar{G}^{t r, b} / w_{g}=\bar{G}^{t r, w} / w_{p}, w_{g}=\rho w_{p}$, decrease in $q$ \\
\hline
\end{tabular}

Table 4: Steady state solutions

\begin{tabular}{|c|c|c|c|c|c|c|}
\hline Variable & Status Quo & Reform 1 & Reform 2 & Reform 3 & Reform 4 & Reform 5 \\
\hline$c^{k}$ & 0.290 & 0.294 & 0.316 & 0.333 & 0.360 & 0.310 \\
\hline$e^{k}$ & 0.154 & 0.156 & 0.171 & 0.174 & 0.186 & 0.163 \\
\hline$k^{k}$ & 9.547 & 9.592 & 9.640 & 9.951 & 10.133 & 9.808 \\
\hline$c^{w}$ & 0.237 & 0.240 & 0.262 & 0.276 & 0.302 & 0.255 \\
\hline$e^{w}$ & 0.309 & 0.311 & 0.313 & 0.314 & 0.318 & 0.312 \\
\hline$c^{b}$ & 0.287 & 0.282 & 0.207 & 0.191 & 0.121 & 0.255 \\
\hline$e^{b}$ & 0.186 & 0.193 & 0.107 & 0.294 & 0.313 & 0.312 \\
\hline$w^{g} / w^{p}$ & 1.03 & 1 & 0.608 & 0.672 & 0.399 & 1 \\
\hline$y$ & 0.363 & 0.364 & 0.366 & 0.378 & 0.385 & 0.373 \\
\hline$y^{g}$ & 0.038 & 0.037 & 0.028 & 0.051 & 0.050 & 0.049 \\
\hline$c / y$ & 0.705 & 0.705 & 0.705 & 0.705 & 0.705 & 0.705 \\
\hline$k / y$ & 3.897 & 3.897 & 3.897 & 3.897 & 3.897 & 3.897 \\
\hline$b / y$ & 0.9 & 0.9 & 0.9 & 0.9 & 0.9 & 0.9 \\
\hline$\tau^{l}$ & 0.295 & 0.283 & 0.204 & 0.181 & 0.099 & 0.247 \\
\hline$s^{w}$ & 0.132 & 0.119 & 0.044 & 0.132 & 0.074 & 0.190 \\
\hline$s^{t r, b}$ & 0.1104 & 0.1104 & 0.1104 & 0.022 & 0.012 & 0.029 \\
\hline$u^{k}$ & -0.798 & -0.799 & -0.815 & -0.743 & -0.730 & -0.760 \\
\hline$u^{w}$ & -0.957 & -0.959 & -0.962 & -0.888 & -0.867 & -0.914 \\
\hline$u^{b}$ & -0.824 & -0.826 & -0.898 & -1.003 & -1.136 & -0.914 \\
\hline$u$ & -0.905 & -0.907 & -0.926 & -0.891 & -0.904 & -0.891 \\
\hline PubSE & 0.456 & 0.463 & 0.534 & 0.577 & 0.746 & 0.454 \\
\hline PrivSE & 1.031 & 1.031 & 1.031 & 1.031 & 1.031 & 1.031 \\
\hline $\begin{array}{l}\text { PubSE / } \\
\text { PrivSE }\end{array}$ & 0.442 & 0.449 & 0.518 & 0.560 & 0.723 & 0.440 \\
\hline
\end{tabular}

Notes: (i) We use the baseline parameterization in Table 1. (ii) $u=v^{p} u^{p}+v^{b} u^{b}$ (the same formula is used for all per capita quantities). 
Table 5: Discounted lifetime utility

\begin{tabular}{|c|c|c|c|}
\hline $\begin{array}{c}\text { Lifetime } \\
\text { utility }\end{array}$ & Status quo & Reform 5 & $\xi$ \\
\hline$U^{k}$ & -79.78 & -74.81 & 0.17 \\
\hline$U^{w}$ & -95.73 & -89.78 & 0.20 \\
\hline$U^{b}$ & -82.38 & -89.78 & -0.25 \\
\hline$U$ & -90.50 & -87.57 & 0.10 \\
\hline
\end{tabular}

Notes: (i) We use the baseline parameterization in Table 1. (ii) $U=v^{k} U^{k}+v^{b} U^{b}+v^{w} U^{w}$. 